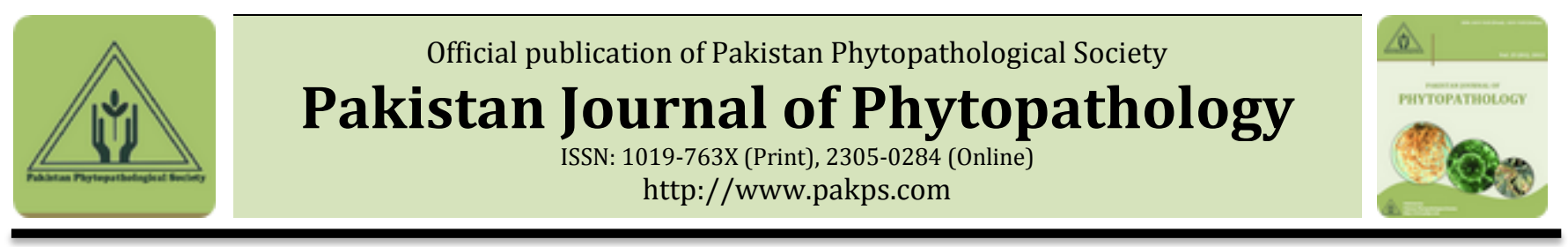

\title{
EVALUATION OF NEEM (AZADIRACHTA INDICA) SEED AND CASSIA ALATA LEAF EXTRACTS AS SURFACE PROTECTANTS AGAINST SEED BORNE FUNGI OF MAIZE (ZEA MAYS L.)
}

\author{
aElias N.K. Sowley*, Ruth A. Ofori, Frederick Kankam \\ Department of Agronomy, Faculty of Agriculture, University for Development Studies, P. O. Box TL1882, Nyankpala \\ Campus, Tamale, Ghana.
}

\section{A B S T R A C T}

Seed borne fungi constitute a major constraint to maize production and this is aggravated by the use of farmer-saved seeds which may be unhealthy. The study was aimed at testing the efficacy of Cassia alata leaf and neem (Azadirachta indica) seed extracts against seed borne fungi. Maize (Zea mays) seeds were obtained from three farmers in each of ten communities randomly selected from the Tolon-Kumbungu district. Seed borne fungi were isolated from seed samples by plating on PDA. Four fungi belonging to three genera namely Aspergillus niger, A. flavus, Botryodiplodia theobromae and Penicillium digitatum were isolated from the seed samples. These fungi were grown on PDA plates amended with aqueous and ethanol extracts of Cassia alata leaf and neem seed, carbendazim and sodium hypochlorite and their radial growth measured. Ethanol extracts of $C$. alata leaf and neem seed were similar but had a higher inhibition than their aqueous extracts. Aqueous extract of $C$. alata leaf inhibited growth to a significantly higher $(\mathrm{P}<0.05)$ extent than aqueous neem seed extract. Although ethanol extracts of $C$. alata leaf and neem seed had a significantly higher $(\mathrm{P}<0.05)$ inhibitory effect, aqueous extract of the former was better than the neem seed extract and may therefore be used by farmers in treating their seeds since ethanol is relatively expensive.

Keywords: Cassia alata, fungi, maize, neem, seed borne

\section{INTRODUCTION}

Maize (Zea mays L.), the world's second most important, widely cultivated and consumed cereal crop is a staple food in Sub-Saharan Africa and serves as a source of income and nutritional security (Purseglove, 1992). There are many constraints against increased production notable among which are pests and diseases which cause appreciable losses. This is supported by Hussain et al., (2013) report that seed borne fungi cause huge losses of maize grains in the field as well as in storage houses. The situation is worsened through the use of farmer-saved seeds by small scale farmers, who are usually ignorant about the health status of those seeds (Somda et al., 2008).

Several fungicides have been tested and recommended for seed treatment but their use is being discouraged because

* Corresponding Author:

Email: esowley@gmail.com

(C) 2017 Pak. J. Phytopathol. All rights reserved. of potential harmful effects and relatively high cost which limits access to poor farmers. Plant extracts of many higher plants have been reported to exhibit antibacterial, antifungal and insecticidal properties (Kuri et al., 2011). Plant metabolites and plant-based pesticides appear to be better alternatives as they are known to have minimal environmental impact and danger to consumers in contrast to the synthetic pesticides (Kuri et al., 2011). Chatterjee (1990) reported that oils of Cassia and clove inhibited the development of seed borne infections of $A$. flavus in maize. Cassia alata and neem abound in the study area, hence it is necessary to evaluate their efficacy against seed borne fungi which affect maize production. The objective of the study was therefore to determine the effectiveness of Cassia alata leaf and neem seed extracts for the control of seed borne fungi of maize.

\section{MATERIALS AND METHODS}

Experimental site: The study was carried out in the Spanish laboratory of the University for Development 
Studies, Nyankpala Campus in the Tolon-Kumbungu district of the Northern Region in Ghana. Nyankpala is located at latitude $9^{\circ} 25^{\prime} 41^{\prime \prime} \mathrm{N}$ and longitude $0^{\circ} 58^{\prime}$ 42" W with an altitude of $200 \mathrm{~m}$. The study area experiences moderate unimodal rainfall which usually last from May to October with the peak occurring between August and September. The mean annual rainfall is $118.64 \mathrm{~mm}$ while the mean monthly maximum rainfall is $10.8 \mathrm{~mm}$. Mean monthly minimum temperatures of $22.4{ }^{\circ} \mathrm{C}$ and maximum of $33.6{ }^{\circ} \mathrm{C}$ have been recorded. The mean monthly minimum relative humidity is $80 \%$.

Collection of seed samples: A total of thirty seed samples were collected according to the ISTA rules from three randomly selected farmers in each of ten randomly selected communities namely Kpalisogu, Kpalisokpana, Woreborgukukuo, Woreborgu, Kpachi, Kokpang, Cheyohe, Balinkpeng, Gbullung and Bontanga.

\section{Isolation and identification of pathogens}

Medium preparation: Potato Dextrose Agar (PDA) (Oxoid Ltd Basingstoke, UK) was prepared as recommended by the manufacturer at the rate of $39 \mathrm{~g}$ of PDA powder per liter of distilled water. The PDA water mixture contained in a conical flask was autoclaved at a temperature of $121^{\circ} \mathrm{C}$ and a pressure of $1.02 \mathrm{Kg} / \mathrm{cm}^{2}$ for $15 \mathrm{~min}$ and then dispensed into 9 cm Petri dishes.

Isolation: One hundred seeds from each sample were surface sterilized in $1 \%$ Sodium hypochlorite solution for $1 \mathrm{~min}$, rinsed three times in sterile distilled water, plated on PDA at 5 seeds per plate and then incubated at room temperature for 7 days under light/dark cycles (Govender et al., 2007). The plates were observed daily for fungal growth. Fungi isolated from the seeds were sub-cultured to obtain pure cultures.

Identification: Identification of the fungal isolates was based on cultural and morphological characteristics described by Barnett and Hunter (2006). Cultural characteristics were observed with the naked eye and a stereomicroscope while mycelia and reproductive structures such as spores were examined with a compound microscope.

\section{Preparation of plant extracts}

Ethanol and Aqueous Extracts of Cassia alata Leaf: Fresh leaves were obtained from a Cassia alata plant and dried under shade for one week. The dried leaves were then ground into powder with a blender. Twenty grams $(20 \mathrm{~g})$ each of the powder was soaked in $100 \mathrm{ml}$ of water and $80 \%$ ethanol. The mixtures were stirred vigorously and left undisturbed overnight before filtering to obtain the extracts.

Ethanol and Aqueous Extracts of Neem Seed: Ripe fruits of neem were collected from trees on the Nyankpala Campus of the University for Development Studies, depulped, washed and dried under shade for 2 days. Kernels were separated from the shells by cracking and winnowing. The kernels were then ground into powder with a blender. About $20 \mathrm{~g}$ of the powder was soaked in $100 \mathrm{ml}$ each of water and $80 \%$ ethanol. The mixtures were stirred vigorously and allowed to stand overnight after which the supernatant was decanted and used as extract (Rahman et al., 2008).

Measurement of Growth inhibition: The effect of Cassia alata leaf and neem seed extracts, sodium hypochlorite and carbendazim on growth of fungi isolated from maize seed was determined based on the method described by Okigbo and Nmeka (2005). This involved creating quadrants on each Petri-dish by drawing two perpendicular lines at the bottom of the plate, the point of intersection indicating the centre of the plate before dispensing Potato Dextrose Agar (PDA) into each of the plates. PDA in $9 \mathrm{~cm}$ Petri dishes was amended with $2 \mathrm{ml}$ of the extracts, $10 \%$ sodium hypochlorite and carbendazim $(0.5 \mathrm{~g} / \mathrm{l})$. A 4$\mathrm{mm}$ diameter disc from pure cultures of A. flavus, $A$. niger, Botryodiplodia theobromae and Penicillium digitatum was placed on the PDA plates at the point of intersection of the two lines drawn at the bottom of the Petri dish. The control did not contain plant extract, sodium hypochlorite or carbendazim. The diameter of each fungal colony was measured daily for 5 days. The percentage colony growth inhibition was calculated using Pandey et al., (1982) formula:

$$
\text { Growth inhibition }(\%)=\frac{D C-D T}{D C} \times 100
$$

where $\mathrm{DC}=$ average diameter of control, and DT= average diameter of fungal colony with treatment.

Data Analysis: The data were subjected to Analysis of Variance with Genstat (9th edition). The Least Significant Difference (LSD) was used to separate the means.

\section{RESULTS}

Percentage occurrence of fungi isolated from maize seeds: Four fungi namely Aspergillus flavus, $A$. 
niger, Botryodiplodia theobromae and Penicllium digitatum were isolated from the seed samples. A. niger had the highest percentage of occurrence
(40.7) followed by A. flavus (30.2), Penicillium digitatum (24.2) and Botryodiplodia theobromae (4.9) (Figure 1).

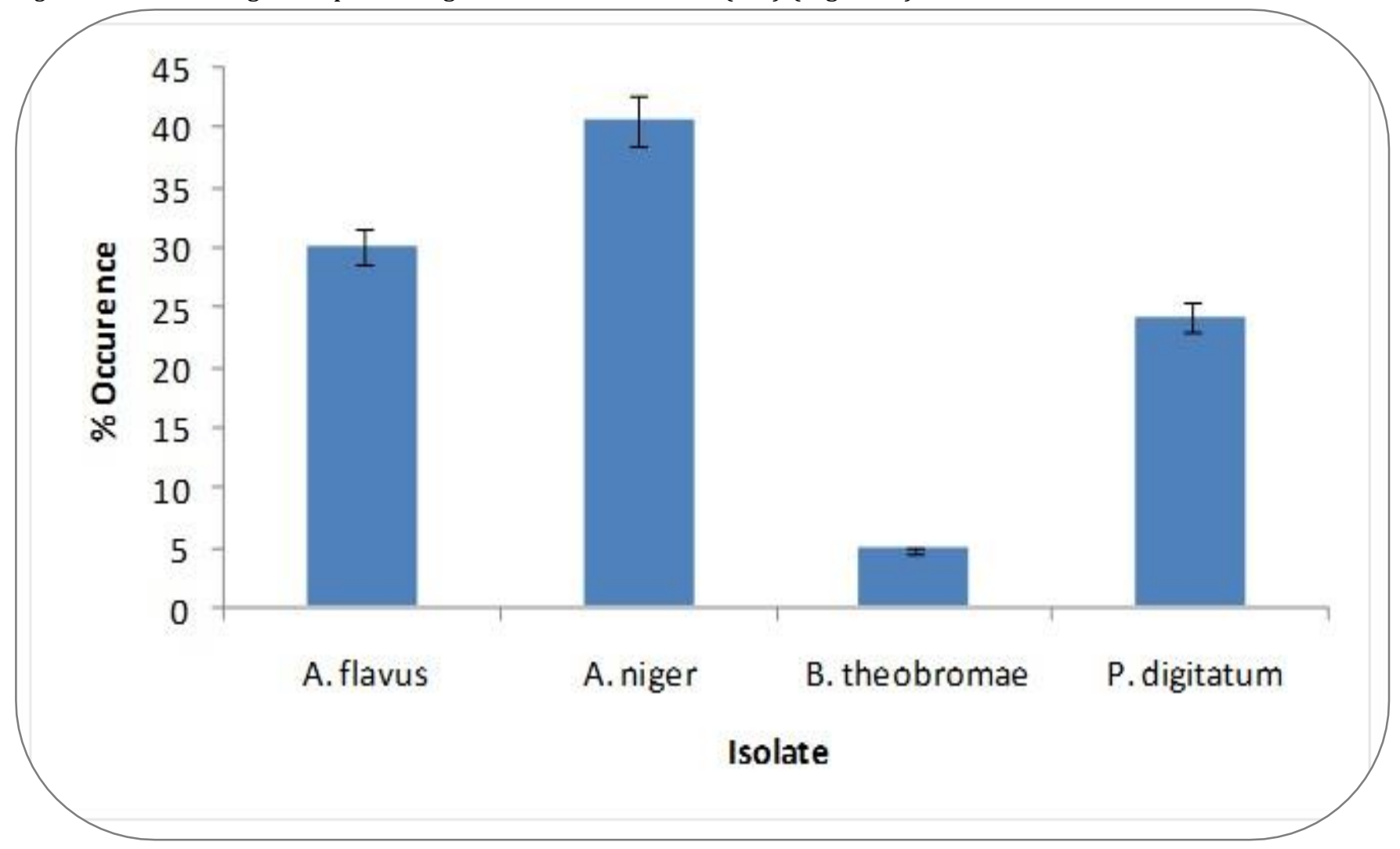

Figure 1. Relative percentage occurrence of seed borne fungi of maize

Effect of aqueous and ethanol plant extracts on similar but had a higher inhibition than their aqueous growth of fungal isolates: Carbendazim, a fungicide did not fully inhibit the growth of the test fungi and its effect was not significantly different $(\mathrm{P}<0.05)$ from sodium hypochlorite for all isolates except $B$. theobromae (Table extracts. Ethanol extract of neem seed had a significantly higher $(\mathrm{P}<0.05)$ inhibitory effect than its aqueous extract. Aqueous extract of $C$. alata leaf inhibited growth to a significantly higher $(\mathrm{P}<0.05)$ extent than aqueous 1). Ethanol extracts of $C$. alata leaf and neem seed were neem seed extract.

Table 1. Inhibition of fungal growth by aqueous and ethanol extracts of neem seed and C. alata leaf

\begin{tabular}{|c|c|c|c|c|c|c|c|}
\hline & & \multirow{4}{*}{$\begin{array}{l}\text { Sodium } \\
\text { hypochlorite }\end{array}$} & \multicolumn{2}{|r|}{ \% Inhibition } & & & \\
\hline \multirow[t]{3}{*}{ Isolate } & \multirow{3}{*}{ Carbendazim } & & & eous & \multicolumn{2}{|r|}{ Ethanol } & \\
\hline & & & C. alata & Neem seed & C. alata & Neem seed & Control \\
\hline & & & & & & & \\
\hline A. flavus & $63.3 a$ & $43.7 a$ & $58.7 a$ & $37 b$ & $60 a$ & $63.3 a$ & Oc \\
\hline A. niger & 89.7a & $89.7 a$ & $61.7 b$ & $12.3 c$ & 87.3a & $88.7 a$ & Oc \\
\hline B. theobromae & $74.7 a$ & $13.7 b$ & $59.7 a$ & $25.3 b$ & $74.7 a$ & $75.7 a$ & Oc \\
\hline P. digitatum & $86.7 a$ & $86.7 a$ & $49.3 b$ & $24.3 c$ & $85.3 a$ & $86 a$ & Oc \\
\hline
\end{tabular}

Means followed by the same letter in a row are not significantly different.

Relative Growth inhibition by extracts of $C$. alata leaf and neem seed: Inhibition of growth by carbendazim (78.6\%) was similar to ethanol extracts of C. alata leaf (76.9\%) and neem seed (78.4\%) which were significantly better $(\mathrm{P}<0.05)$ than sodium hypochlorite (58.5\%), aqueous C. alata (57.4\%), aqueous neem seed $(24.7 \%)$ and the control $(0 \%)$ (Figure 2). 


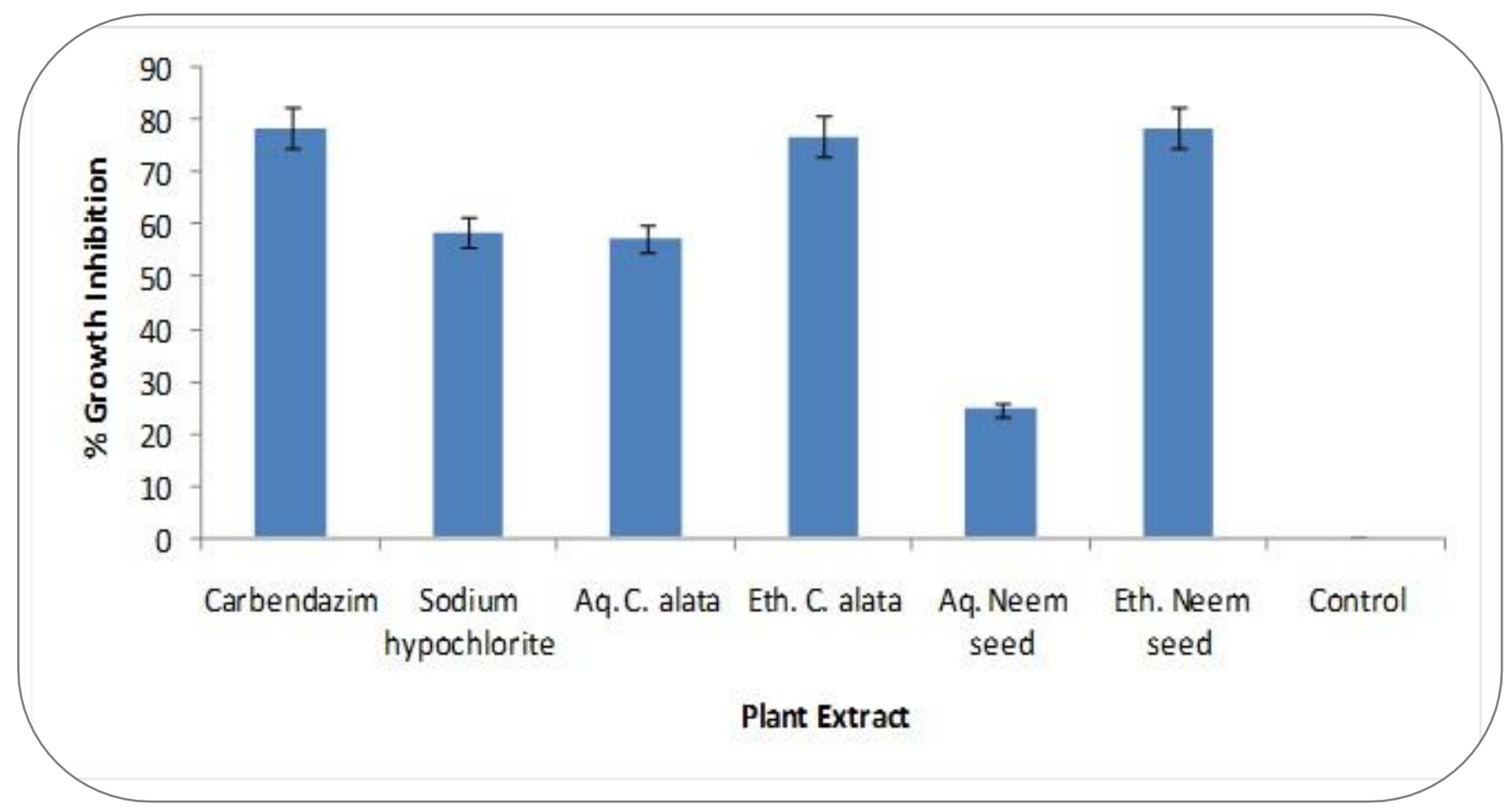

Figure 2. Relative efficacy of $C$. alata and neem seed extracts.

\section{DISCUSSION}

Occurence of fungi: Four fungi namely A. niger, A. flavus, Botyrodiplodia theobromae and Penicillium digitatum, were isolated with $A$. niger showing the highest occurrence. In a similar study, Niaz and Dawar (2009) isolated Aspergillus flavus, A. wentii and Penicillium digitatum from maize seeds with A. niger showing the highest percentage of occurrence. On the contrary, Saleem et al., (2012) reported that A. flavus (94\%) showed the highest incidence in maize seed collected from different areas in Pakistan followed by A. niger (62\%) and Fusarium moniliforme (43\%). In another study, Adjei (2011) isolated Acremonium strictum, Bipolaris maydis, Botryodiplodia theobromae and Fusarium moniliforme from maize seeds. Hussain et al., (2013) also isolated Fusarium and Aspergillus spp. amongst others with $A$. niger and $F$. moniliforme being the most prevalent. Sitara and Akhter (2007) isolated several pathogens from maize seed including Aspergillus niger, A. flavus, A wenii, Fusarium oxysporum, F. moniliforme, F. semitectum and $F$. nivale.

Effect of plant extracts on growth of fungi: The seed borne fungi of maize responded differently to plant extracts. Aqueous extract of C. alata leaf inhibited growth to a significantly higher $(\mathrm{P}<0.05)$ extent than aqueous neem seed extract. Inhibition of growth by carbendazim (78.6\%) was similar to ethanol extracts of
C. alata leaf $(76.9 \%)$ and neem seed $(78.4 \%)$. This does not conform to the report by Sitara and Akhter (2007) that Ridomyl Gold was most effective in controlling seed borne mycoflora of maize followed by neem seed powder, Aliette, Antracol and Sodium hypochlorite. Mondali et al., (2009) reported that aqueous and ethanol extracts of neem leaf inhibited the growth of Rhizopus and Aspergillus significantly. They also reported that ethanol extracts were more effective than aqueous extracts which is a confirmation of the findings of this study. Suleiman (2011) reported the inhibition of Aspergillus viridae, Penicillium digitatum and Rhizopus sp. with neem (Azadirachta indica) and tobacco (Nicotiana tabacum) extracts with the latter completely inhibiting Aspergillus viridae and Penicillium digitatum at $60 \%$ concentration. Suleiman and Falaiye (2013) reported that neem leaf extract suppressed mycelial growth of $A$. niger at $30 \%$ and $40 \%$ concentration. Owolade et al., (2000) reported that aqueous extracts of Ocimum gratissimum, Acalypha ciliate, Vernonia amyygdalina and Mangifera indica significantly inhibited the growth of Fusarium monioliforme, a seed borne pathogen of maize.

\section{CONCLUSION}

A. niger had the highest occurrence followed by $A$. flavus, Penicillium digitatum and Botryodiplodia theobromae. Although ethanol extracts of C. alata leaf 
and neem seed had a significantly higher $(\mathrm{P}<0.05)$ inhibitory effect, aqueous extract of the former was better than the aqueous neem seed extract. Since ethanol is expensive, farmers could use aqueous leaf extract of $C$. alata in treating seeds prior to planting.

\section{REFERENCES}

Adjei, F. 2011. Investigation into fungal seed borne pathogens of farmer-saved seed maize (Zea mays L.) collected from three ecological zones of Ghana and efficacy of plant extracts in controlling the pathogens. MSc. Thesis, Kwame Nkrumah University of Science and Technology, Kumasi, Ghana.

Barnett H. L. and B. B. Hunter. 2006. Illustrated genera of imperfect fungi. 4th ed. St. Paul (MN): American Phytopathological Society.

Chatterjee, D. 1990. Inhibition of fungal growth and infection of maize grains by spice oils. Lett. Appl. Microbiol. 11: 148-151.

Govender, V., T. A. S. Aveling, and Q. Kritzinger. 2007. The effect of traditional storage methods on germination and vigour of maize (Zea mays L.) from northern KwaZulu-Natal and southern Mozambique. South Afr. J. Bot. 74: 190-196.

Hussain N., A. Hussain, M. Ishtiaq, S. Azam, and T. Hussain. 2013. Pathogenicity of two seed-borne fungi commonly involved in maize seeds of eight districts of Azad Jammu and Kashmir Pakistan. Afr. J. Biotechnol. 12(12): 1363-1370.

Kuri, S. K., R. M. Islam, and U. Mondal. 2011. Antifungal potentiality of some botanical extracts against important seed borne fungal pathogen associated with brinjal seeds, Solanum melongena L. J. Agric. Technol. 7 (4): 1139-1153.

Mondali, N. K., A. Mojumdar, S. K. Chatterje, A. Banerjee, J. K. Datta and S. Gupta. 2009. Antifungal activities and chemical characterization of Neem leaf extracts on the growth of some selected fungal species in vitro culture medium. J. Appl. Sci. Environ. Manag. 13(1): 49-53.
Niaz, I. and S. Dawar. 2009. Detection of seed borne mycoflora in maize (Zea mays L.). Pak. J. Bot. 41(1): 443-451.

Okigbo, R. N. and I. A. Nmeka. 2005. Control of yam tuber rot with leaf extracts of Xylopia aethiopica and Zingiber officinale. Afr. J. Biotechnol. 4: 404-807.

Owolade, O. F., A. N. Amusa, and Y. O. K. Osikanlu. 2000. Efficacy of certain indigenous plant extracts against seed borne infection of Fusarium moniliforme on maize (Zea mays L.) in South Western Nigeria. Cereal Res. Commun. 28(3): 323-327.

Pandey, D. K., N. N. Tripathi, R. O. Tripathi, S. N. Dixit. 1982. Fungitoxic and Phytotoxic properties of essential oil of Phylis sauvolensis. Pfkrankh. Pfschutz. 89:344-346.

Purseglove, J. W. 1992. Tropical Crops: Monocotyledons. Longman Scientific and Technical, New York. pp. 300-305.

Rahman, M. S., M. Y. Ali, and M. U. Ali. 2008. In vitro screening of two flavonoid compounds isolated from Cassia alata L. leaves for fungicidal activities. J. Bio-Sc. 16: 139-142.

Saleem, M. J., R. Bajwa, A. Hannan, and T. A. Qaiser. 2012. Maize seed storage mycoflora in Pakistan and its chemical control. Pak. J. Bot. 44(2): 807-812.

Sitara, U. and S. Akhter. 2007. Efficacy of fungicides, sodium hypochlorite and neem seed powder to control seed borne pathogens of maize. Pak. J. Bot. 39(1): 285-292.

Somda, I., J. Sanou, and P. Sanon. 2008. Seed borne infection of farmer-saved maize seeds by pathogenic fungi and their transmission to seedlings. Plant Pathol. J. 7(1): 98-103.

Suleiman, M. N. 2011. Antifungal properties of leaf extract of neem and tobacco on three fungal pathogens of tomato (Lycopersicon esculentum Mill). Adv. Appl. Sc. Res. 2 (4): 217-220.

Suleiman, M. N. and T. N. Falaiye. 2013. In vitro control on fungus associated with biodeterioration of sweet potato (Ipomoea batatas (L.) LAM) tubers. FUTA J. Res. Sc. 1: 1-7. 